\title{
Trends in idiopathic inflammatory myopathies: cross-sectional data from the German National Database
}

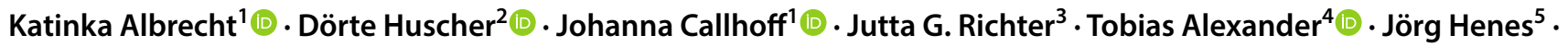 \\ Angela Zink ${ }^{1,4}(\mathbb{C}$
}

Received: 18 May 2020 / Accepted: 17 June 2020 / Published online: 27 June 2020

(c) The Author(s) 2020

\begin{abstract}
Objective To describe trends in outcomes among patients with idiopathic inflammatory myopathies (IIM) over two decades. Methods From 1997 to 2017, a total of 1079 IIM patients were documented in the National Database of the German Collaborative Arthritis Centers. Annual cross-sectional data on treatment, disease activity, patient-reported outcomes, hospitalization and employment were compared across the years. Information on phenotypes, organ manifestations and autoantibodies was collected for a subset to compare the assessment of global health, pain, fatigue and sleeping disorders.

Results In 2017, significantly more IIM patients were assessed to be in low disease activity (94\%) than in 1997 (59\%), $p<0.01$. Pain $(p=0.001)$, global health $(p=0.049)$, fatigue $(p=0.03)$ and sleeping disorders $(p=0.01)$ also improved since recording. Glucocorticoid use decreased from 84 to $58 \%(p<0.01)$. Employment in patients $<65$ years remained unchanged (53\%), while early retirement (23-9\%), hospitalization/year (34-18\%) and sick leave (52-24\%) decreased. A total of 186 patients with information on subtypes were classified as polymyositis (44\%), dermatomyositis (33\%), anti-synthetase syndrome (10\%), overlapping-myositis (8\%), inclusion body myositis (2\%), necrotizing myositis $(0.5 \%)$ and unspecific (3\%). The most frequently reported symptoms were limitations in global health (60\%), fatigue (57\%) and sleeping disorders (51\%), and all of them were most frequent in overlap-myositis. Pulmonary hypertension and cardiomyopathy were associated with poor outcomes regarding global health, daily activities and fatigue.
\end{abstract}

Conclusion IIM patients report better outcomes than 20 years ago, along with good physician-reported disease control. Global health, fatigue and sleeping disorders are relevant patient-reported domains in IIM.

Keywords Idiopathic inflammatory myopathies $\cdot$ Polymyositis $\cdot$ Dermatomyositis $\cdot$ Patient-reported outcomes

Katinka Albrecht

albrecht@drfz.de

Dörte Huscher

doerte.huscher@charite.de

Johanna Callhoff

Johanna.callhoff@drfz.de

Jutta G. Richter

richterj@uni-duesseldorf.de

Tobias Alexander

tobias.alexander@charite.de

Jörg Henes

Joerg.Henes@med.uni-tuebingen.de

Angela Zink

zink@drfz.de
1 German Rheumatism Research Centre, Epidemiology Unit, Charitéplatz 1, 10117 Berlin, Germany

2 Charité Universitätsmedizin, Institute of Biostatistics and Clinical Epidemiology, Berlin, Germany

3 Medical Faculty, Policlinic for Rheumatology and Hiller Research Centre for Rheumatology, Heinrich-Heine-University Duesseldorf, Duesseldorf, Germany

4 Department of Rheumatology and Clinical Immunology, Charité Universitätsmedizin, Berlin, Germany

5 Department of Rheumatology and Clinical Immunology, Eberhard Karls-University of Tuebingen, Tuebingen, Germany 


\section{Introduction}

Idiopathic inflammatory myopathies (IIM) are a heterogeneous group of inflammatory muscle diseases that involve muscle weakness and visceral involvement, resulting in disability and impaired quality of life [1-3]. As IIM are rare among inflammatory rheumatic diseases, it is difficult to collect data for outcome research with a sufficient number of patients. In 2011, the Outcome Measures in Rheumatology (OMERACT) Myositis Special Interest Group was established to examine patient-reported outcome measures in myositis [4]. They required additional focus on patients with different myositis disease phenotypes and manifestations across a range of disease activity. Results from the OMERACT multicenter focus groups indicated that some of the patient-reported symptoms such as pain and fatigue have not been sufficiently assessed in myositis patients [5]. Due to the scarcity of patients with IMM, the data were often compiled or referred to small patient numbers $[6,7]$. International collaborative research within the Euro Myositis registry enabled to increase patient numbers and therefore facilitates myositis research [8]. Until sufficient data are available, further efforts are made to focus on a core set of patient-reported domains, incorporating the patient perspective on the prioritization of outcomes $[9,10]$. The modified patient-reported outcome core domain set includes muscle symptoms, fatigue, level of physical activity and pain as mandatory outcomes to assess in IIM [11]. In the German National Database (NDB) of the Collaborative Arthritis Centers, patient-reported outcomes have been documented for many years. The NDB was specifically conceptualized to provide data on health care for all patients with inflammatory rheumatic diseases. Although documentation is tailored to rheumatoid arthritis being the most frequently reported disease, data on spondyloarthritis, connective tissue diseases and vasculitis are also collected [12]. Patients with IIM have been observed since 1993. The aim of the present study was to describe trends in core domains such as fatigue, pain and other outcomes regarding work ability and hospitalization among patients with IIM over the last 20 years.

\section{Patients and methods}

Cross-sectional data were derived from the National Database of the German Collaborative Arthritis Centers (NDB) between 1997 and 2017. The NDB is an ongoing prospective study which was established in 1993 as a long-term monitoring database for German rheumatology. Participating rheumatologists from 15 to 17 centers consecutively include unselected outpatients with inflammatory rheumatic diseases. Centers comprise both private practices and tertiary outpatient clinics. The database provides annually updated information on patients with inflammatory rheumatic diseases under rheumatologic care, covering data on sociodemographic parameters, laboratory tests, therapies, clinical and patient-reported outcomes, as well as additional health information [13]. Patients with IIM were identified by confirmed ICD-10 diagnosis of M33.0 (juvenile dermatomyositis), M33.1 (other dermatomyositis), M33.2 (polymyositis) or M33.9 (other dermatomyositis-polymyositis, not specified), International Classification of Diseases, 10th Edition. There was no patient in the NDB with main diagnosis of G72.4 (inflammatory myopathy, not elsewhere classified).

\section{Annual documentation}

For each year, treatment is reported including the following substances: NSAIDs, glucocorticoids, azathioprine, methotrexate, cyclosporine A, cyclophosphamide, antimalarials, TNF inhibitors (since 2000), mycophenolate mofetil (since 2005), rituximab (since 2006). The glucocorticoid dose was categorized into $<7.5$ and $\geq 7.5 \mathrm{mg}$ prednisolone equivalent per day. Disease activity is assessed by the rheumatologist on a numerical rating scale (NRS) with values ranging from 0 (no activity) to 10 (highest activity). Physicians also report on the presence of the following comorbid conditions: hypertension, cardiac disease, osteoporosis, osteoarthritis, diabetes, renal disease, depression and malignant neoplasm (yes/no). Utilization of physiotherapy within the last 12 months was reported by the patient until 2005 and from 2006 onward by the physician.

Patient-reported outcomes include pain, global health (since 2000), fatigue, physical activities, sleeping disorders, coping, emotional and physical well-being (all since 2007). All of them are assessed on NRS (0-10) that are derived from the rheumatoid arthritis impact of the disease (RAID) [14] and that are also used in other connective tissue diseases $[12,15]$. Functional status is assessed by the Hannover Functional Ability Questionnaire $(\mathrm{FFbH})$ ranging from 0 (no functional capacity) to 100 (full functional capacity) [16]. Anxiety/depression and daily activities (no/moderate/extreme) are assessed by the EuroQol 5D [17]. Patients were asked about their employment status (Are you full-time employed/part-time employed/unemployed/retired/in early retirement?), sick leave (Have you been on sick leave due to your inflammatory disease during the past 12 months?) and hospitalization (Have you been treated as an inpatient due to your inflammatory rheumatic disease during the last 12 months?). 


\section{Myositis questionnaire}

As information on IIM phenotype, myositis-specific autoantibodies and organ manifestations is not captured in the NDB, a supplementary questionnaire was sent out once in 2015 . The rheumatologists were asked to complete the additional items for all 232 patients with IIM who had been documented between 2007 and 2015, covering data on the diagnostic subtype, in particular dermatomyositis (DM), polymyositis (PM), anti-synthetase syndrome (ASS), connective tissue diseaseoverlap, necrotizing myopathy and inclusion body myositis (assigned by the rheumatologist), confirmation of diagnosis (biopsy, magnetic resonance imaging, creatine kinase (CK), transaminase enzymes and/or antibodies), antibody tests and specification, if positive (Anti-Jo-1, anti-RNA, anti-Mi-2, anti-SRP, anti-HMG-CoA, anti-MDA-5 or other), history of organ involvement: skin, muscular, arthritis, dysphagia, interstitial lung disease, pulmonary hypertension, cardiomyopathy, Raynaud/telangiectasia or other, CK values (U/l) and the manual muscle testing (MMT8) score, if available.

\section{Statistical analyses}

Descriptive statistics (mean, standard deviation (SD) and percentages) were used to summarize patients' characteristics, treatments and outcomes for each calendar year. As the NDB exists for more than two decades, several variables have been added at certain time points. If applicable, the year in which a new variable was added is reported. To account for a case mix bias regarding disease duration, physician-reported disease activity and patient-reported outcomes are displayed by disease duration categories ( $<5$ years, $5-10$ years, $>10$ years).

To test whether outcomes have improved over time, patientreported outcomes were compared with the Cochrane-Armitage test for trend.

From the supplementary questionnaire, the frequencies of phenotypes, diagnostics, organ involvement and autoantibodies are reported. Patients' characteristics, comorbidities and patient-reported outcomes are reported for PM, DM, ASS and overlap-myositis. Patients were not reclassified if myositisspecific antibodies, e.g., Anti-Jo-1, were positive.

Ethical approval was obtained from the Ethics Committee of the Charité - University Medicine Berlin (EA1/196/06) in February 2007. This research was conducted in agreement with the Declaration of Helsinki.

\section{Results}

\section{Cross-sectional trends}

\section{Characteristics}

From 1997 to 2017, a total of 1079 patients (2355 visits) with IIM were documented in the NDB. Annually, the visits of 34 (in 2005) to 187 patients (in 2000) were recorded. Since 2005, the number of participating institutions and consequently the number of patients have decreased due to a switch to electronic documentation. Between $76 \%$ (1997) and 60\% (2015) of the patients were female without a trend in the proportion over the years. Over the period of 20 years, the mean age increased from 52 to 58 years. The proportion of patients with long disease duration also increased over the years (Table 1).

\section{Treatments}

Glucocorticoids were used less frequently in the more recent years (58\% vs. 84\%), $p<0.001$. Glucocorticoid doses $\geq 7.5 \mathrm{mg}$ were also used significantly less often (17\% vs. $46 \%, p<0.001)$. Azathioprine has been used less often in the recent years (26\%), while methotrexate was used slightly more commonly (32\%). Rituximab is used since 2006 , and in $2017,13 \%$ of the patients received rituximab. All immunosuppressive treatments are reported in Table 1 . The prescription of physiotherapy was reported in $20 \%-34 \%$ of the patients, without a trend over the years.

\section{Physician- and patient-reported outcomes}

Physicians have rated disease activity in recent years much lower than 20 years ago. In 2017, 94\% of the patients reached low disease activity according to the physician assessment.

Over the years, the percentages of patients with favorable ratings on patient-reported outcomes increased significantly. The outcome gradings "low", "good" and "little" were defined as $\leq 3$ on a $0-10$ NRS. In $2017,75 \%$ of the patients reported to have low pain compared to $47 \%$ in 1997. A good global health was reported by $51 \%$ of patients vs. $34 \%$ in 2002 , little fatigue by $63 \%$ vs. $43 \%$ in 2007 and little sleeping disorders by $60 \%$ vs. $41 \%$ in 2007 (Table 2). No or little limitations in activities of daily living applied to $63 \%$ vs. $44 \%$ in 2007 , and no anxiety/depression was reported by $75 \%$ vs. $53 \%$ in 2007 , all $p<0.05$. Details on outcomes are reported in Table 2. 
Table 1 Patient characteristics 1997-2017

\begin{tabular}{|c|c|c|c|c|c|c|c|c|c|c|c|}
\hline$N$ & & $\begin{array}{l}1997 \\
170\end{array}$ & $\begin{array}{l}1999 \\
174\end{array}$ & $\begin{array}{l}2001 \\
175\end{array}$ & $\begin{array}{l}2003 \\
161\end{array}$ & $\begin{array}{l}2007 \\
64\end{array}$ & $\begin{array}{l}2009 \\
81\end{array}$ & $\begin{array}{l}2011 \\
94\end{array}$ & $\begin{array}{l}2013 \\
82\end{array}$ & $\begin{array}{l}2015 \\
83\end{array}$ & $\begin{array}{l}2017 \\
72\end{array}$ \\
\hline Women, \% & & 76 & 72 & 76 & 73 & 63 & 62 & 65 & 66 & 60 & 72 \\
\hline Age (years), mean & & 52 & 53 & 53 & 52 & 55 & 56 & 55 & 57 & 57 & 58 \\
\hline Age at disease onset (years), mean & & 46 & 46 & 46 & 44 & 46 & 47 & 47 & 48 & 47 & 48 \\
\hline \multirow[t]{4}{*}{ Symptom duration (years), $\%$} & $\leq 2$ years & 30 & 28 & 24 & 25 & 25 & 21 & 15 & 15 & 5 & 9 \\
\hline & $2-5$ years & 29 & 32 & 28 & 26 & 20 & 23 & 25 & 19 & 30 & 17 \\
\hline & $5-10$ years & 20 & 23 & 29 & 22 & 25 & 20 & 33 & 39 & 30 & 34 \\
\hline & $>10$ years & 21 & 17 & 20 & 27 & 29 & 37 & 27 & 28 & 34 & 40 \\
\hline \multicolumn{12}{|l|}{ Medication } \\
\hline Nonselective NSAIDs, $\%$ & & 13 & 12 & 9 & 7 & 18 & 18 & 19 & 22 & 16 & 13 \\
\hline Glucocorticoids, $\%$ & & 84 & 82 & 82 & 71 & 78 & 81 & 78 & 73 & 66 & 58 \\
\hline of those & $<7.5 \mathrm{mg}$ & 54 & 56 & 54 & 59 & 60 & 71 & 80 & 79 & 88 & 83 \\
\hline Azathioprine, $\%$ & & 39 & 36 & 40 & 41 & 22 & 34 & 33 & 31 & 32 & 26 \\
\hline Methotrexate, $\%$ & & 20 & 26 & 29 & 20 & 29 & 21 & 33 & 35 & 34 & 32 \\
\hline Cyclosporine A, \% & & 3 & 2 & 2 & 5 & 16 & 16 & 12 & 10 & 9 & 7 \\
\hline Cyclophosphamide, \% & & 7 & 10 & 13 & 8 & 2 & 1 & 1 & & 3 & 3 \\
\hline Antimalarials, $\%$ & & 9 & 7 & 4 & 7 & 4 & 6 & 5 & 6 & 7 & 4 \\
\hline Mycophenolate mofetil, \% & Since 2005 & & & & & 4 & 9 & 9 & 6 & 8 & 8 \\
\hline TNF inhibitors, $\%$ & Since 2000 & & & 0 & 0 & 0 & 0 & 0 & 0 & 4 & 1 \\
\hline Rituximab, \% & Since 2006 & & & & & 2 & 4 & 5 & 7 & 7 & 13 \\
\hline
\end{tabular}

NSAIDs nonsteroidal antirheumatic drugs, TNF tumor necrosis factor

Due to a small case number the year 2005 is omitted

Improved patient-reported outcomes and physicianreported disease activity were observed in all disease duration categories (Fig. 1).

\section{Hospitalization and work participation}

Fewer patients were hospitalized due to IIM in 2017 (18\%) compared to 1997 (34\%). Employment of patients $<65$ years was 53\% in both 1997 and 2017. Among employed patients, sick leave due to IIM during the last 12 months decreased from $52 \%$ in 1997 to $24 \%$ in 2017 . The proportion of patients with early retirement decreased from 23 to $9 \%$ (patients $\leq 65$ years) (Table 3 ).

\section{Comparison of subtypes from supplementary questionnaire}

The supplementary questionnaire was available for 187 patients (Table 4). Physician-reported subtypes were PM $(n=82,44 \%), \mathrm{DM}(n=62,33 \%)$, ASS $(n=18,10 \%)$, overlap ( $n=15,8 \%)$, inclusion body myositis $(n=3,2 \%)$, necrotizing myositis $(n=1,0.5 \%)$ or unspecific subtype $(n=5$, $3 \%$ ). In $11 \%$, the patients were assigned to two phenotypes, mostly PM and overlap or PM and ASS. When diagnostic confirmation was performed, $82 \%$ showed $\mathrm{CK} /$ transaminase elevation, $66 \%$ myositis-specific antibodies, $87 \%$ muscle biopsy and 79\% MRI findings. CK values differed considerably and were lowest in patients with DM and overlap. The MMT8 score was only obtained in 5 cases.

Of 131 patients with known autoantibody status, $66 \%$ had positive autoantibodies: Anti-Jo-1 $(57 \%, n=49)$, anti-Mi-2 $(7 \%, n=6)$, anti-SRP $(5 \%, n=4)$ and other (documented as ANA, ENA, SSA, RNP, PM-Scl, PL-7, proteasome, RO, Scl-70: $27 \%, n=35$ ). Anti-Jo-1 was present in all physicianreported subtypes: $\mathrm{PM}(56 \%, n=23)$, DM $(33 \%, n=5)$, overlap $(36 \%, n=4)$ and ASS $(94 \%, n=16)$.

While muscular involvement was frequent across all subtypes (78-87\%), other organ manifestations varied considerably. ILD (83\%) and arthritis (56\%) were predominant in ASS, skin affection (73\%) in DM, Raynaud (40\%) and cardiomyopathy (13\%) in overlap-myositis. If any myositis-specific autoantibodies, especially Anti-Jo-1 antibodies, were present, patients had more frequently interstitial lung disease $(61 \%$ vs. $17 \%, p<0.001)$ and arthritis ( $43 \%$ vs. $16 \%, p<0.001)$, but had less often skin involvement $(12 \%$ vs. $42 \%, p<0.001)$.

While hypertension and osteoporosis were most frequent in overlap-myositis, malignant neoplasms were found in $9 \%$ of patients with DM and osteoarthritis (29\%) was more common in ASS.

In those 186 patients, the most frequently self-reported symptoms were limitations in global health (60\%), fatigue 
Table 2 Physician and patientreported outcomes 1997-2017, all $\%$ $\begin{array}{llllllllll}1997 & 1999 & 2001 & 2003 & 2007 & 2009 & 2011 & 2013 & 2015 & 2017\end{array}$

\begin{tabular}{|c|c|c|c|c|c|c|c|c|c|c|}
\hline \multicolumn{11}{|l|}{ Physician-reported } \\
\hline \multicolumn{11}{|l|}{ Disease activity } \\
\hline Low $(0-3)$ & 59 & 58 & 64 & 65 & 76 & 82 & 77 & 87 & 91 & 94 \\
\hline Moderate (4-6) & 33 & 36 & 26 & 28 & 20 & 15 & 19 & 10 & 7 & 6 \\
\hline Severe $(7-10)$ & 8 & 6 & 9 & 7 & 4 & 3 & 4 & 3 & 1 & \\
\hline \multicolumn{11}{|l|}{ Patient-reported } \\
\hline \multicolumn{11}{|l|}{ Physical function } \\
\hline Low limitation $(>70)$ & 53 & 59 & 53 & 68 & 65 & 65 & 65 & 66 & 61 & 66 \\
\hline Limited (50-70) & 26 & 19 & 24 & 11 & 10 & 13 & 12 & 9 & 20 & 16 \\
\hline In need of help $(\leq 50)$ & 22 & 22 & 22 & 21 & 25 & 22 & 23 & 25 & 20 & 18 \\
\hline \multicolumn{11}{|l|}{ Pain } \\
\hline Low $(0-3)$ & 47 & 50 & 51 & 50 & 46 & 52 & 58 & 58 & 55 & 75 \\
\hline Moderate (4-6) & 34 & 27 & 30 & 32 & 36 & 32 & 22 & 24 & 30 & 17 \\
\hline Severe $(7-10)$ & 19 & 23 & 19 & 18 & 18 & 17 & 20 & 19 & 15 & 8 \\
\hline \multicolumn{11}{|l|}{ Global health, since 2000} \\
\hline Good $(0-3)$ & & & 35 & 36 & 36 & 32 & 43 & 37 & 42 & 51 \\
\hline Moderate (4-6) & & & 39 & 43 & 45 & 55 & 35 & 46 & 26 & 37 \\
\hline Poor (7-10) & & & 26 & 21 & 20 & 13 & 22 & 17 & 32 & 12 \\
\hline \multicolumn{11}{|l|}{ Fatigue, since 2007} \\
\hline Little $(0-3)$ & & & & & 43 & 46 & 43 & 48 & 50 & 63 \\
\hline Moderate (4-6) & & & & & 37 & 31 & 33 & 23 & 31 & 19 \\
\hline Severe $(7-10)$ & & & & & 20 & 24 & 25 & 28 & 19 & 17 \\
\hline \multicolumn{11}{|c|}{ Sleeping disorder, since 2007} \\
\hline Little $(0-3)$ & & & & & 41 & 57 & 41 & 62 & 52 & 60 \\
\hline Moderate (4-6) & & & & & 37 & 25 & 33 & 22 & 29 & 21 \\
\hline Severe $(7-10)$ & & & & & 22 & 18 & 26 & 17 & 19 & 19 \\
\hline \multicolumn{11}{|c|}{ Anxiety/depression, since 2007} \\
\hline No & & & & & 53 & 60 & 66 & 65 & 72 & 75 \\
\hline Moderate & & & & & 43 & 40 & 29 & 34 & 24 & 25 \\
\hline Severe & & & & & 4 & & 4 & 2 & 4 & \\
\hline
\end{tabular}

Outcomes are reported on numeric rating scales from 0 to 10 [14]. Physical function is reported from $0-100,100$ representing full function [16]
(57\%) and sleeping disorders (51\%), and all of them were most frequent in overlap-myositis (Fig. 2). Patients with pulmonary hypertension $(n=5)$ and cardiomyopathy $(n=15)$ showed poor cross-sectional outcomes on global health, physical activities and fatigue [18].

\section{Discussion}

With a total of 1079 patients, data from a comparatively large number of patients with IIM have been collected in the NDB over the past 20 years. Overall, a trend toward a better disease activity control with reduced needs of glucocorticoids was observed. Patient-reported outcomes on disease burden, work ability and hospitalization also improved. In 2017, 1 of 8 patients received rituximab and a further increase in more specific and effective therapies can be expected in future. Besides rituximab, baricitinib, triple regimens and other new treatment options bear the potential to improve the situation of patients with IIM [19].

Immunosuppressive treatment was less frequently used compared to the European registry [8]. Irrespective of the myositis phenotype, mean glucocorticoid doses remained above $7.5 \mathrm{mg}$ prednisone equivalent daily in a relevant number of patients, indicating the need for more efficacious treatments. A Cochrane review reports a lack of high-quality RCTs that assess the efficacy and toxicity of immunosuppressants in inflammatory myositis [20]. So far, methotrexate and azathioprine showed similar survival rates as first-line immunosuppressives in a retrospective cohort [21] and they are also the most frequently used substances in our database.

As expected, organ involvement followed the diagnostic classification with ILD and arthritis associated with ASS and skin manifestation associated with DM. Patients suffering 


\section{Disease activity (0-10)}

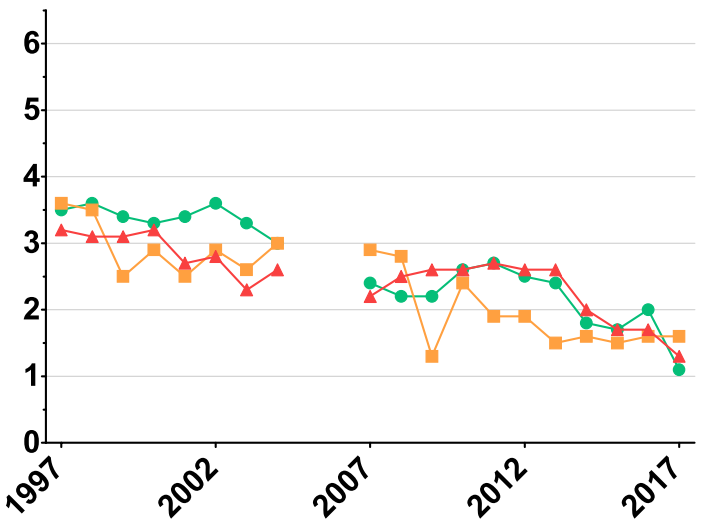

Pain (0-10)

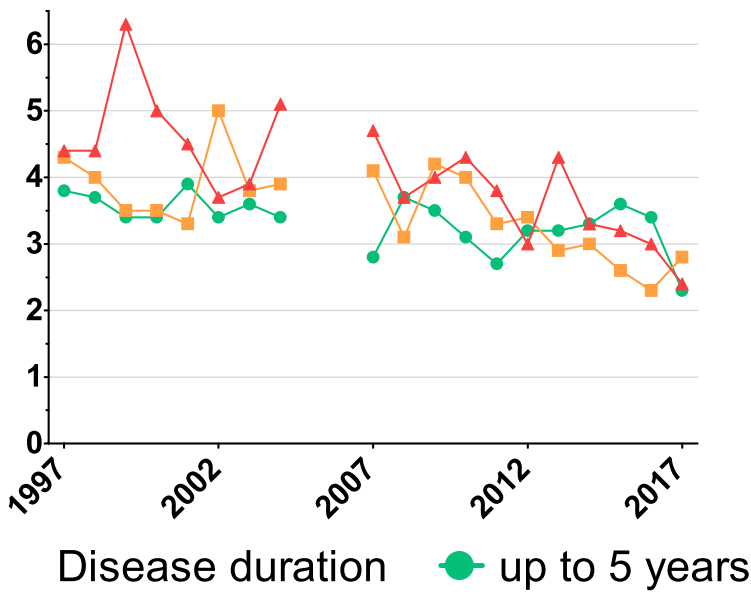

Fig. 1 Trends in outcomes in inflammatory myopathies 1997-2017. Displayed are mean values of numeric ratings from 0 to 10 . Disease activity is reported by the rheumatologist ( 0 : no activity to 10 : highest

\section{Patient Global (0-10)}

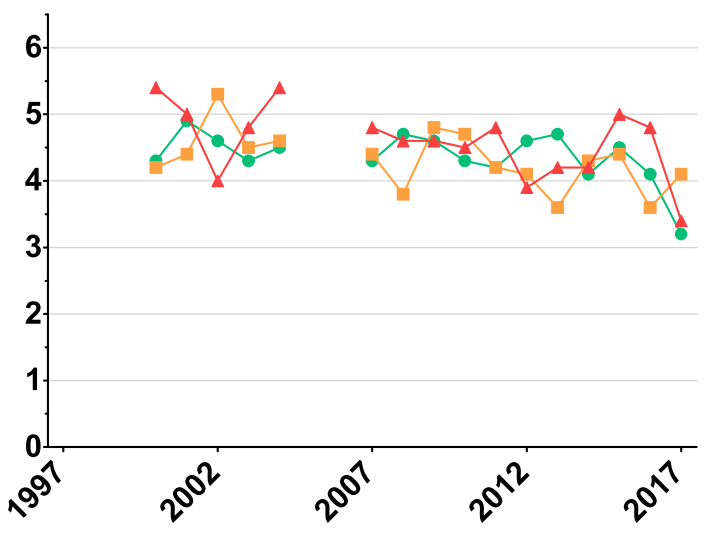

Fatigue (0-10)

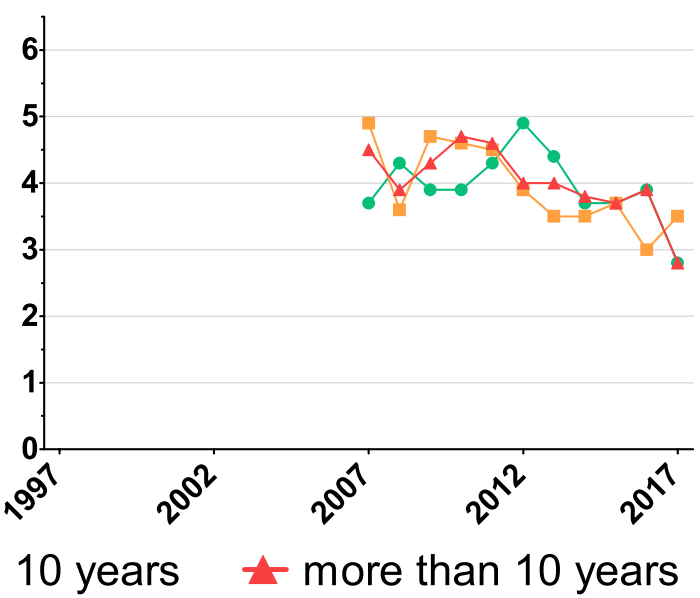

activity). Patient global, pain and fatigue are reported by the patients (0: no to 10 worst). The years 2005 and 2006 are omitted due to case numbers $<50$

Table 3 Hospitalization and work participation 1997-2017

\begin{tabular}{|c|c|c|c|c|c|c|c|c|c|c|}
\hline & 1997 & 1999 & 2001 & 2003 & 2007 & 2009 & 2011 & 2013 & 2015 & 2017 \\
\hline Hospitalized due to IIM in the past year, \% & 34 & 38 & 32 & 26 & 32 & 17 & 19 & 13 & 15 & 18 \\
\hline Persons $<65$ years old, $N$ & 142 & 131 & 138 & 123 & 47 & 57 & 65 & 54 & 57 & 46 \\
\hline Employed ( $<65$ years old), $\%$ & 53 & 45 & 39 & 39 & 44 & 38 & 47 & 47 & 53 & 53 \\
\hline Employed part time among employed, $\%$ & - & & & & 12 & & & & & 24 \\
\hline $\begin{array}{l}\text { Sick leave due to IIM in the past year among } \\
\text { employed, } \%\end{array}$ & 52 & 26 & 46 & 44 & 50 & 38 & 50 & 27 & 26 & 24 \\
\hline Early retirement $(<65$ years old), $\%$ & 23 & 27 & 32 & 31 & 27 & 38 & 33 & 24 & 22 & 9 \\
\hline
\end{tabular}

IIM Idiopathic inflammatory myopathies

from cardiac manifestation and pulmonary hypertension frequently reported poor outcomes on all PRO dimensions. The dimensions most frequently reported by all myositis patients were fatigue and limitations in global health, while severe pain was reported by one-fifth. A systematic review on health-related quality of life in myositis patients revealed 
Table 4 Subanalysis: characteristics by physician-reported phenotypes

\begin{tabular}{|c|c|c|c|c|c|}
\hline & Total & PM & DM & ASS & Overlap \\
\hline$N$ & 187 & 82 & 62 & 18 & 15 \\
\hline \multicolumn{6}{|l|}{ Characteristics } \\
\hline Sex, female n $(\%)$ & $113(61)$ & $50(61)$ & $40(65)$ & $8(44)$ & $12(80)$ \\
\hline Age, mean (SD) & $59(14)$ & $61(13)$ & $58(14)$ & $57(14)$ & $51(18)$ \\
\hline \multicolumn{6}{|c|}{ Autoantibodies $n(\%)$, total $n=131$} \\
\hline Any autoantibodies & $86(66)$ & $41(71)$ & $15(41)$ & $17(94)$ & $11(79)$ \\
\hline Of those Anti-Jo-1 & $49(57)$ & $23(56)$ & $5(33)$ & $16(94)$ & $4(36)$ \\
\hline Mi2 & $6(7)$ & $2(5)$ & $4(27)$ & $0(0)$ & $0(0)$ \\
\hline SRP & $4(5)$ & $4(10)$ & $0(0)$ & $0(0)$ & $0(0)$ \\
\hline \multicolumn{6}{|c|}{ Organ manifestation $n(\%)$, total $n=186$} \\
\hline Muscular & $157(84)$ & $71(87)$ & $51(82)$ & $14(78)$ & $13(87)$ \\
\hline Skin & $59(32)$ & $3(4)$ & $45(73)$ & $3(17)$ & $7(47)$ \\
\hline Arthritis & $45(24)$ & $20(24)$ & $9(15)$ & $10(56)$ & $6(40)$ \\
\hline $\begin{array}{l}\text { Interstitial lung } \\
\text { disease }\end{array}$ & $46(25)$ & $13(16)$ & $12(19)$ & $15(83)$ & $4(27)$ \\
\hline Dysphagia & $26(14)$ & $12(15)$ & $11(18)$ & $0(0)$ & $2(13)$ \\
\hline $\begin{array}{l}\text { Raynaud/telangiec- } \\
\text { tasia }\end{array}$ & $18(10)$ & $5(6)$ & $4(7)$ & $3(17)$ & $6(40)$ \\
\hline Cardiomyopathy & $15(8)$ & $5(6)$ & $6(10)$ & $1(6)$ & $2(13)$ \\
\hline $\begin{array}{l}\text { Pulmonary hyperten- } \\
\text { sion }\end{array}$ & $5(3)$ & $0(0)$ & $4(7)$ & $1(6)$ & $0(0)$ \\
\hline \multicolumn{6}{|c|}{ Comorbidities, $n(\%)$, total $n=157$} \\
\hline Hypertension & $71(45)$ & $34(49)$ & $26(46)$ & $4(24)$ & $7(54)$ \\
\hline $\begin{array}{l}\text { Coronary heart } \\
\text { disease }\end{array}$ & $33(22)$ & $19(26)$ & $11(19)$ & $2(12)$ & $1(8)$ \\
\hline Osteoporosis & $30(19)$ & $14(20)$ & $11(19)$ & $2(12)$ & $3(23)$ \\
\hline Osteoarthritis & $32(21)$ & $16(23)$ & $10(18)$ & $5(29)$ & $1(8)$ \\
\hline Diabetes & $25(15)$ & $15(21)$ & $8(14)$ & $1(6)$ & $1(8)$ \\
\hline Renal disease & $19(12)$ & $9(13)$ & $6(11)$ & $3(18)$ & $1(8)$ \\
\hline Depression & $13(8)$ & $6(9)$ & $5(9)$ & $1(6)$ & $1(8)$ \\
\hline Malignant neoplasm & $13(8)$ & $7(10)$ & $5(9)$ & $0(0)$ & $1(0)$ \\
\hline
\end{tabular}

$P M$ Polymyositis, DM dermatomyositis, ASS anti-synthetase syndrome

Due to the small number of cases, the other phenotypes are not listed

the need for further studies because existing data were scarce and heterogeneous [2]. Our data support a very heterogeneous picture of myositis patients, making it difficult to obtain robust results referring to small patient groups.

Limitations and Strengths. We report cross-sectional data, so that no causal relationship can be drawn regarding the source of outcome impairments. Organ involvement was reported as ever and may be treated sufficiently, so that it does not interfere with PROs anymore. Patient numbers on ASS, overlap, inclusion body myositis and necrotizing myositis were low, and these are not suitable to acquire robust data. As the NDB covers a wide range of inflammatory rheumatic diseases, specific data on IIM are lacking. The 2017 EULAR classification criteria cannot be applied [22]. The retrospective collection of additional myositisspecific information was a way to counter this limitation but is not a sufficient substitute for prospective data collection. Today, numerous disease-specific standardized and validated core set measures such as the Myositis Activities Profile (MAP) are available [23]. However, they are not used in everyday clinical practice. The NDB illustrates the routine rheumatological care in rheumatic centers in Germany. The Manual Muscle Testing (MMT) was collected only in 3\% of IIM patients. Therefore, cross-disease measuring tools may be an appropriate tool for mapping changes over time in patients from routine care. The strength of the NDB is the long-term monitoring of PROs, enabling to provide valid data on the impairment regarding fatigue, pain and other general symptoms in a sufficient number of myositis patients. With pain, fatigue and sleeping disorders, three of the patient-prioritized domains [10] are available for a long observation period. However, muscle symptoms as the main domain in the OMERACT core set [11] are not reported. Recent advances in the outcome assessment of myositis including patient-reported outcome measures enable a more specific future outcome research in patients with IIM [24, 25].

We can conclude from our data that in the NDB, physician-reported disease activity and patient-reported disease burden in IIM have improved within the last 20 years. Fatigue, impaired global health and sleeping disorders are frequently reported domains in IIM that may be considered in future research. 

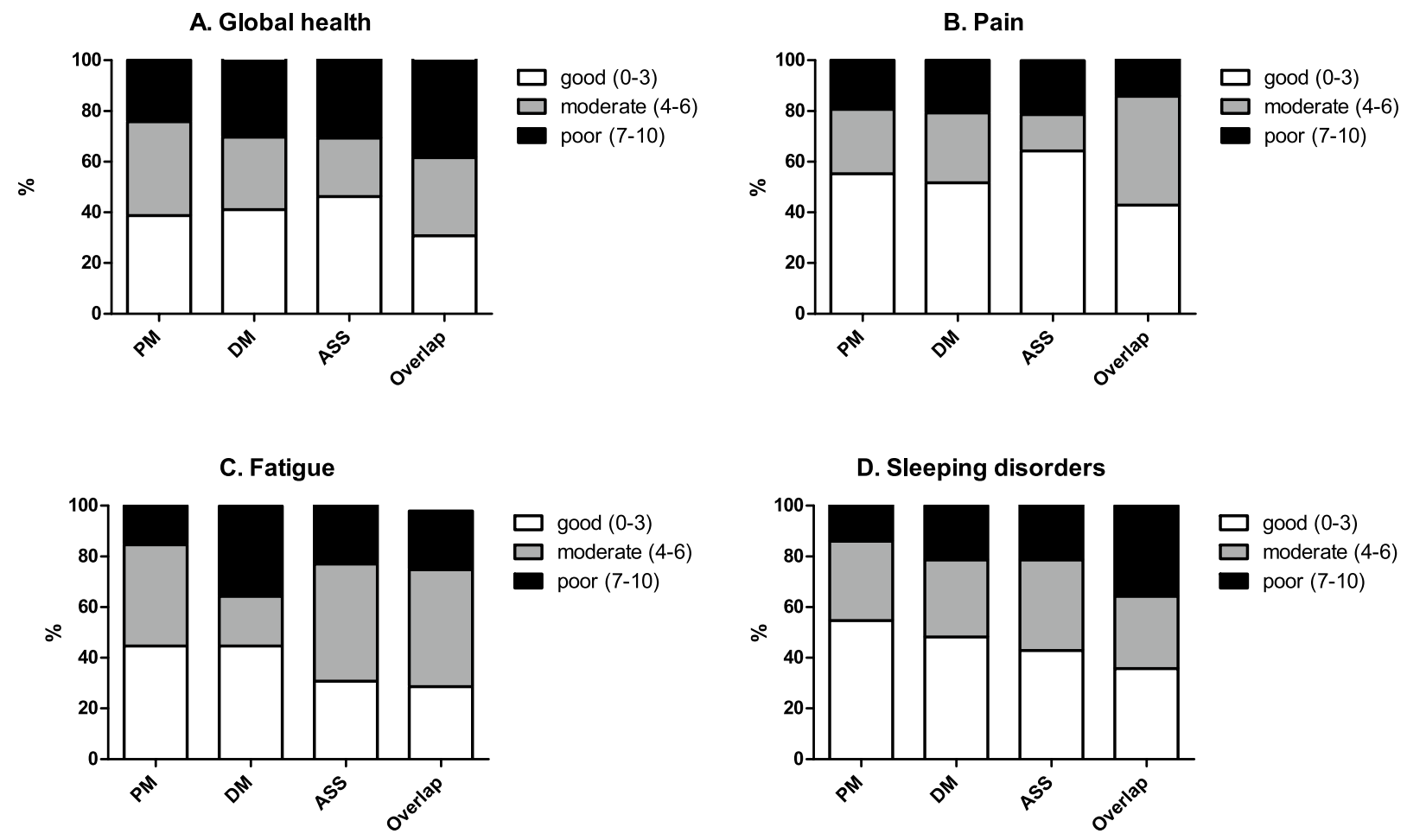

Fig. 2 Patient-reported outcomes in idiopathic inflammatory myopathies. $P M$ Polymyositis, $D M$ dermatomyositis, $A S S$ anti-synthetase syndrome, overlap overlapping-myositis, all classified by the rheumatologist. All outcomes were assessed on numeric rating scales (0-10)

Acknowledgements Open Access funding provided by Projekt DEAL. The authors gratefully acknowledge the contributions and the enthusiasm of all participating patients and consultant rheumatologists who contributed data to the National Database. In particular, the authors would like to acknowledge the significant contributions of R Alten (Berlin), M Aringer (Dresden), H Burkhardt (Frankfurt/Main), S Kleinert and J Wendler (Erlangen), T Eidner (Jena), K Fischer (Greifswald), U von Hinüber (Hildesheim), G Hoese (Stadthagen), K Karberg (Berlin), I Kötter (Hamburg), A Krause (Berlin), W Ochs (Bayreuth), S Späthling-Mestekemper (München), S Wassenberg and R Weier (Ratingen). We thank Katja Thiele, Sascha Bischoff and Gregor Förster for their valuable support in data management.

Author contributions All authors contributed to the study conception and design. Data were contributed by Jutta Richter, Jörg Henes and Tobias Alexander. Data analyses and interpretation were performed by Katinka Albrecht, Dörte Huscher, Johanna Callhoff, Jutta Richter and Angela Zink. The first draft of the manuscript was written by Katinka Albrecht, and all authors commented on previous versions of the manuscript. All authors read and approved the final and revised manuscript.

Funding The National Database of the German Collaborative Arthritis Centers has been supported since 2007 by the Association of Regional Cooperative Rheumatology Centres and joint contributions to the Rheumatological Training Academy and the DRFZ by the following members of the Working Group of Corporate Members of the German Society for Rheumatology: AbbVie, Actelion, BMS, GSK, Medac, MSD, Pfizer, Roche, Sanofi-Aventis and UCB. The principal investigators and their team had full academic freedom in study design and conduct, data analysis and publication of results. The data interpretation, drafting, critical revision and approval of the final manuscript were performed solely by the authors.

Data availability Availability of data and material: No additional data are available.

Conflicts of interest The authors state that there are no conflicts of interest.

Open Access This article is licensed under a Creative Commons Attribution 4.0 International License, which permits use, sharing, adaptation, distribution and reproduction in any medium or format, as long as you give appropriate credit to the original author(s) and the source, provide a link to the Creative Commons licence, and indicate if changes were made. The images or other third party material in this article are included in the article's Creative Commons licence, unless indicated otherwise in a credit line to the material. If material is not included in the article's Creative Commons licence and your intended use is not permitted by statutory regulation or exceeds the permitted use, you will need to obtain permission directly from the copyright holder. To view a copy of this licence, visit http://creativecommons.org/licenses/by/4.0/.

\section{References}

1. Marie I (2012) Morbidity and mortality in adult polymyositis and dermatomyositis. Curr Rheumatol Rep 14:275-285

2. Leclair V, Regardt M, Wojcik S, Hudson M, Canadian Inflammatory Myopathy S (2016) Health-related quality of life (HRQoL) 
in idiopathic inflammatory myopathy: a systematic review. PLoS ONE 11:e0160753

3. Feldon M, Farhadi PN, Brunner HI, Itert L, Goldberg B, Faiq A et al (2017) Predictors of reduced health-related quality of life in adult patients with idiopathic inflammatory myopathies. Arthritis Care Res (Hoboken) 69:1743-1750

4. Alexanderson H, Del Grande M, Bingham CO 3rd, Orbai AM, Sarver C, Clegg-Smith K et al (2014) Patient-reported outcomes and adult patients' disease experience in the idiopathic inflammatory myopathies. Report from the OMERACT 11 Myositis Special Interest Group. J Rheumatol 41:581-592

5. Regardt M, Basharat P, Christopher-Stine L, Sarver C, Bjorn A, Lundberg IE et al (2015) Patients' experience of myositis and further validation of a myositis-specific patient reported outcome measure - establishing core domains and expanding patient input on clinical assessment in myositis. Report from OMERACT 12. J Rheumatol 42:2492-2495

6. Marie I, Lahaxe L, Benveniste O, Delavigne K, Adoue D, Mouthon L et al (2010) Long-term outcome of patients with polymyositis/ dermatomyositis and anti-PM-Scl antibody. Br J Dermatol 162:337-344

7. Regardt M, Welin Henriksson E, Alexanderson H, Lundberg IE (2011) Patients with polymyositis or dermatomyositis have reduced grip force and health-related quality of life in comparison with reference values: an observational study. Rheumatology (Oxford) 50:578-585

8. Lilleker JB, Vencovsky J, Wang G, Wedderburn LR, Diederichsen LP, Schmidt J et al (2018) The EuroMyositis registry: an international collaborative tool to facilitate myositis research. Ann Rheum Dis 77:30-39

9. Park JK, Mecoli CA, Alexanderson H, Regardt M, Christopher-Stine L, Casal-Dominguez M et al (2017) Advancing the development of patient-reported outcomes for adult myositis at OMERACT 2016: An international Delphi Study. J Rheumatol 44:1683-1687

10. Mecoli CA, Park JK, Alexanderson H, Regardt M, Needham M, de Groot I et al (2019) Perceptions of patients, caregivers, and healthcare providers of idiopathic inflammatory myopathies: an international OMERACT study. J Rheumatol 46:106-111

11. Regardt M, Mecoli CA, Park JK, de Groot I, Sarver C, Needham $\mathrm{M}$ et al (2019) OMERACT 2018 modified patient-reported outcome domain core set in the life impact area for adult idiopathic inflammatory myopathies. J Rheumatol 46:1351-1354

12. Callhoff J, Thiele K, Dorner T, Zink A, Richter JG, Henes $\mathrm{J}$, et al (2019) Trends in employment and hospitalisation in patients with Sjogren's syndrome 1996-2016: results from the German National database. Clin Exp Rheumatol 37 Suppl 118(3):83-89

13. Albrecht K, Callhoff J, Zink A (2019) Long-term trends in rheumatology care : Achievements and deficits in 25 years of the German national rheumatology database. Z Rheumatol 78(Suppl 2):65-72

14. Gossec L, Paternotte S, Aanerud GJ, Balanescu A, Boumpas DT, Carmona $L$ et al (2011) Finalisation and validation of the rheumatoid arthritis impact of disease score, a patient-derived composite measure of impact of rheumatoid arthritis: a EULAR initiative. Ann Rheum Dis 70:935-942
15. Albrecht K, Huscher D, Richter J, Backhaus M, Bischoff S, Kotter I et al (2000s) Changes in referral, treatment and outcomes in patients with systemic lupus erythematosus in Germany in the 1990s and the 2000s. Lupus Sci Med 1(1):e000059

16. Lautenschlager J, Mau W, Kohlmann T, Raspe HH, Struve F, Bruckle W et al (1997) Comparative evaluation of a German version of the Health Assessment Questionnaire and the Hannover Functional Capacity Questionnaire. Z Rheumatol 56:144-155

17. Janssen MF, Pickard AS, Golicki D, Gudex C, Niewada M, Scalone L et al (2013) Measurement properties of the EQ-5D-5L compared to the EQ-5D-3L across eight patient groups: a multicountry study. Qual Life Res 22:1717-1727

18. Carstens PO, Schmidt J (2014) Diagnosis, pathogenesis and treatment of myositis: recent advances. Clin Exp Immunol $175: 349-358$

19. Glaubitz S, Zeng R, Schmidt J (2020) New insights into the treatment of myositis. Ther Adv Musculoskel Dis 12:1-14

20. Gordon PA, Winer JB, Hoogendijk JE, Choy EH (2012) Immunosuppressant and immunomodulatory treatment for dermatomyositis and polymyositis. Cochrane Database Syst Rev 15:CD003643

21. Schiopu E, Phillips K, MacDonald PM, Crofford LJ, Somers EC (2012) Predictors of survival in a cohort of patients with polymyositis and dermatomyositis: effect of corticosteroids, methotrexate and azathioprine. Arthritis Res Ther 27(14):R22

22. Lundberg IE, Tjarnlund A, Bottai M, Werth VP, Pilkington C, de Visser M et al (2017) 2017 European league against rheumatism/ american college of rheumatology classification criteria for adult and juvenile idiopathic inflammatory myopathies and their major subgroups. Arthritis Rheumatol 69:2271-2282

23. Rider LG, Werth VP, Huber AM, Alexanderson H, Rao AP, Ruperto N et al (2011) Measures of adult and juvenile dermatomyositis, polymyositis, and inclusion body myositis: Physician and Patient/Parent Global Activity, Manual Muscle Testing (MMT), Health Assessment Questionnaire (HAQ)/Childhood Health Assessment Questionnaire (C-HAQ), Childhood Myositis Assessment Scale (CMAS), Myositis Disease Activity Assessment Tool (MDAAT), Disease Activity Score (DAS), Short Form 36 (SF-36), Child Health Questionnaire (CHQ), physician global damage, Myositis Damage Index (MDI), Quantitative Muscle Testing (QMT), Myositis Functional Index-2 (FI-2), Myositis Activities Profile (MAP), Inclusion Body Myositis Functional Rating Scale (IBMFRS), Cutaneous Dermatomyositis Disease Area and Severity Index (CDASI), Cutaneous Assessment Tool (CAT), Dermatomyositis Skin Severity Index (DSSI), Skindex, and Dermatology Life Quality Index (DLQI). Arthritis Care Res (Hoboken) 63(Suppl 11):S118-157

24. Rider LG, Aggarwal R, Machado PM et al (2018) Update on outcome assessment in myositis. Nat Rev Rheumatol 14:303-318

25. DiRenzo D, Bingham CO III, Mecoli CA (2019) Patient-reported outcomes in adult idiopathic inflammatory myopathies. Curr Rheumatol Rep 21:62

Publisher's Note Springer Nature remains neutral with regard to jurisdictional claims in published maps and institutional affiliations. 